\title{
INFLUENCE OF SANDBLASTING PARAMETERS AND LUTING MATERIALS ON MICROSHEAR BOND STRENGTH TO A CAD/CAM HYBRID CERAMIC MATERIAL
}

\author{
Sayed Ghorab* and Dina S. Farahat**
}

\begin{abstract}
Objective: To assess the influence of sandblasting parameters (applied pressure and grain particle size) on the microshear bond strength ( $\mu \mathrm{SBS}$ ) of Vita Enamic (VE) CAD/CAM hybrid ceramic to two different resin cements.

Materials and Methods: One-hundred VE specimens were fabricated and allocated to 5 pretreatment groups ( $\mathrm{n}=20 /$ group): no treatment, $50 \mu \mathrm{m} \mathrm{Al}_{2} \mathrm{O}_{3}(2 \mathrm{bar}), 50 \mu \mathrm{m} \mathrm{Al} \mathrm{O}_{3}(3.5 \mathrm{bar}$ ), $110 \mu \mathrm{m} \mathrm{Al}_{2} \mathrm{O}_{3}\left(2 \mathrm{bar}\right.$ ) and $110 \mu \mathrm{m} \mathrm{Al}_{2} \mathrm{O}_{3}(3.5 \mathrm{bar})$. After pretreatment, surface roughness (Ra) was determined using a profilometer. The topography of pretreated surfaces was examined with Scanning Electron Microscopy (SEM). Each group was further divided into two subgroups according to type of luting material; subgroup (a): G-CEM LinkAce and subgroup (b): Single bond universal and RelyX Ultimate. After bonding, $\mu$ SBS was measured with a Universal Testing Machine. Data were statistically analyzed using ANOVA and Tukey HSD tests $(\alpha=.05)$.
\end{abstract}

Results: Specimens air-abraded with $110 \mu \mathrm{ml}_{2} \mathrm{O}_{3}$ and pressure 2 bar showed the highest but insignificant $\mu$ SBS compared to other sandblasted groups $(\mathrm{P}<0.05)$. $\mu$ SBS values $(\mathrm{MPa})$ improved in the following order: $110 \mu \mathrm{m}(2 \mathrm{bar})>50 \mu \mathrm{m}(2 \mathrm{bar})>110 \mu \mathrm{m}(3.5 \mathrm{bar})>50 \mu \mathrm{m}(3.5 \mathrm{bar})>$ control. Regardless the $\mathrm{Al}_{2} \mathrm{O}_{3}$ size, $\mu \mathrm{SBS}$ improved when sandblasting pressure was 2 bar while decreased with 3.5 bar groups. RelyX Ultimate showed higher $\mu$ SBS than G-CEM LinkAce.

Conclusions: Sandblasting of VE surface by ( 2 bar) pressure and the use of conventional resin cement in association with universal adhesive system were required to achieve satisfactory bond strength values.

KEYWORDS: CAD/CAM hybrid ceramic, Luting cements, Microshear bond strength

* Associate Professor of Dental Biomaterials, Faculty of Dentistry, Mansoura University

** Lecturer of Dental Biomaterials, Faculty of Dentistry, Mansoura University 


\section{INTRODUCTION}

The development of CAD/CAM (computer-aided design/computer-aided manufacturing) technology has caused a dramatic effect on different dental disciplines. The rapidly evolving technology has led to a decrease in the number of clinical steps required to fabricate a dental restoration, shorter processing times and more control for the practitioner over the fabrication of unique indirect restorations. ${ }^{1}$ In restorative dentistry, blocks fabricated from various ceramic materials such as feldspathic glass ceramics, lithium disilicate glass ceramics and leucite-reinforced glass ceramics have been used with CAD/ CAM to fabricate indirect esthetic restorations. These materials exhibit superior esthetics, color stability, wear resistance and excellent biocompatibility. However, brittleness and the abrasive effect of these materials on opposing dentition remain challenges encountered when used to fabricate indirect restorations. ${ }^{2}$ Resin-based composites are another class of materials that can be used to fabricate esthetic restorations using $\mathrm{CAD} / \mathrm{CAM}$ technologies. They are mainly composed of an organic polymer matrix that is reinforced with fillers that may be inorganic, organic or both. ${ }^{3}$ The appeal of these materials can be attributed to their lower abrasiveness, ease of fabrication and intra-oral repair and their lower liability to chipping during the milling process. Nevertheless, these materials suffer from color instability, low wear resistance and a higher failure rate when compared to restorations milled from ceramics. $^{4}$

Different efforts have been directed to formulate materials that combine the advantages of both polymers and ceramics resulting in the development of hybrid ceramics. Vita Enamic is a polymer infiltrated ceramic network (PICN) hybrid material that is available as blocks for CAD/CAM processing. ${ }^{4,5}$ It is composed of a main ceramic network (86 wt $\%$ ) consisting of a fine-structured feldspar matrix rich in aluminum oxide that is infiltrated by acrylate polymers (14 wt $\%$ ) such as urethane dimethacrylate (UDMA) and others. During manufacturing, the ceramic powder is compressed and sintered to form an interconnected porous network which is then treated by coupling agents to promote the adhesion with its polymer counterpart. The polymer infiltrates the ceramic network by capillary action then is polymerized under controlled high temperature and pressure to form the hybrid material. ${ }^{6}$ Polymerization under standardized industrial conditions produces materials with homogenous structures with the resulting improvement in their properties. These PICN materials were reported to have properties between composite resins and porcelains, mirroring their microstructures. ${ }^{7}$ They were shown to exhibit lower elastic moduli and hardness values but equal or even higher fracture toughness and minimal edge chipping compared to many glass ceramics and porcelain materials. ${ }^{4}$

Adhesive properties, which are essential for a satisfactory service and durable stability of dental fixed prosthesis, are greatly influenced by the surface treatments performed during the bonding procedure. ${ }^{8}$ Therefore, various researches have been performed to investigate the bond strength between polymer infiltrated ceramic network material and resin composite using different surface pretreatments. ${ }^{6,-14}$ Examples of these treatments include sandblasting (airborne particle abrasion), ${ }^{6,13}$ phosphoric acid application, ${ }^{11,14}$ silica coating, ${ }^{11,14}$ diamond bur grinding, ${ }^{11,13,14}$ etching with hydrofluoric acid (HF) and/or silanization ${ }^{6,11-14}$ and using of Er,Cr:YSGG laser. ${ }^{15}$ Based on the results gained from these studies, airborne particle abrasion could be suggested as one of the best initial surface pretreatment choices of this hybrid ceramic material. However, to the best of our knowledge, the different parameters of this process such as the particle size of the blasting material and the amount of pressure applied during the procedure have not been studied in detail yet. Furthermore, the influence of different 
luting resin cements, after sandblasting, is of great importance since resin cements can infiltrate the porous surface of the substrate to form resin tags, significantly influencing the micro-mechanical retention in order to attain a long-lasting bond.

Thus, the aim of this study was to investigate the effect of varying the pressure and abrasive particles size, used during airborne alumina particle abrasion pretreatment, on the micro shear bond strength $(\mu \mathrm{SBS})$ values of a CAD/CAM hybrid ceramic material luted to two different composite resin cement materials. The null hypothesis of this study was that neither the pretreatment (particle grain size and pressure) nor the type of resin cement has an influence on the $\mu$ SBS between the hybrid ceramic material and the used composite resin cements.

\section{MATERIALS AND METHODS}

\section{Specimen preparation}

Vita Enamic (VE) (Vita Zahnfabrick, BadSa“ckingen, Germany) CAD/CAM hybrid ceramic material was utilized in this study. Compositions, manufacturers and the batch numbers of the materials employed in this study are shown in Table 1. In this study, a sample size of 100 specimens (20 specimens for each surface treatment) was selected to give $95 \%$ power to the present results (effect size $=.55, \alpha=.05$ ) based on the findings of a previous similar study design done by Stawarczyk et $\mathrm{al}^{16}$, who found a significant difference in bond strength values among 5 different surface treatments using variant types of adhesives. A total of one hundred squared-specimens $(10 \times 10 \times 3 \mathrm{~mm})$ were sectioned from VE blanks using a water cooled diamond wafering blade with a low-speed cutting saw (Isomet 4000, Buehler Ltd, Lake Bluff, IL, USA). The specimens were fixed in acrylic resin (Acrostone, Anglo-Egyptian Company, Cairo, Egypt) enclosed in silicone molds. Silicon carbide papers $(400,600$ and 1500-grit) were used to polish the exposed surfaces of the specimens under continuous water irri- gation. Subsequently, specimens were ultrasonically cleaned for $5 \mathrm{~min}$ (Baioden Ultrasonic Cleaner, China) and then left to air dry.

\section{Grouping of specimens}

Specimens were divided randomly into five groups of 20 specimens depending on their surface treatments, as follows; Group A: No surface treatment, Group B: Sandblasting with $50 \mu \mathrm{m}$ $\mathrm{Al}_{2} \mathrm{O}_{3}$ particles (JNBP-2, Jianian Futong Medical Equipment Co. Ltd., Tianjin, China) at a pressure of 2 bar (0.2 MPa), Group C: Sandblasting with $50 \mu \mathrm{m}$ $\mathrm{Al}_{2} \mathrm{O}_{3}$ and pressure of $3.5 \mathrm{bar}(0.35 \mathrm{MPa})$, Group D: Sandblasting with $110 \mu \mathrm{m} \mathrm{Al}_{2} \mathrm{O}_{3}$ and a pressure of 2 bar (0.2 MPa) and Group E: Sandblasting with 110 $\mu \mathrm{m} \mathrm{Al}_{2} \mathrm{O}_{3}$ and pressure of 3.5 bar $(0.35 \mathrm{MPa})$. All groups; except control group, were sandblasted for $10 \mathrm{sec}$ at a working distance of $10 \mathrm{~mm}$.

\section{Surface roughness measurement}

Ten specimens from each group were randomly chosen to evaluate surface roughness using a profilometer (SURFTEST SJ-201, Mitutoyo Corp., Japan). Measurements were done in three different directions after placing the probe in the middle of the surface of each specimen with a traversing length of $0.8 \mathrm{~mm}$ and a constant measuring speed of $0.5 \mathrm{~mm} / \mathrm{sec}$. Average surface roughness (Ra) of each specimen was calculated.

\section{Surface topography examination}

The surface topography of each pretreatment group was examined under a Scanning Electron Microscopy (SEM) (JSM-6510LV, Jeol, Tokyo, Japan). For this purpose, two additional specimens from each pretreatment group were fixed on metallic stubs then gold sputter-coated (SPI-MODULE ${ }^{\mathrm{TM}}$, SPI Supplies, USA) and evaluated under SEM at magnification of 2000X to evaluate any alterations in surface topography that might have occurred due to surface treatment. 
TABLE (1) Materials used in the study

\begin{tabular}{|c|c|c|}
\hline Material & Composition & Manufacturer/Batch No. \\
\hline $\begin{array}{l}\text { CAD/CAM hybrid ceramic } \\
\text { VITA ENAMIC }\end{array}$ & $\begin{array}{l}\text { - } 86 \text { wt } \% \text { feldspathic-based ceramic network } \\
\text { - } 14 \text { wt } \% \text { acrylate polymer network (infiltrated into } \\
\text { ceramic network) }\end{array}$ & $\begin{array}{l}\text { VITA Zahnfabrik, BadSäckingen, } \\
\text { Germany/100003 }\end{array}$ \\
\hline $\begin{array}{l}\text { Luting materials } \\
\text { G-CEM LinkAce }{ }^{\mathrm{TM}} \\
\text { (self adhesive dual-cure resin } \\
\text { cement) }\end{array}$ & $\begin{array}{l}\text { Paste A:Fluoro-alumino-silicate glass, UDMA, } \\
\text { dimethacrylate, } \mathrm{SiO}_{2} \text {, initiator, inhibitor } \\
\text { Paste } \mathrm{B}: \mathrm{SiO}_{2}, \mathrm{UDMA} \text {, dimethacrylate, initiator, inhibitor } \\
\text { Base paste: methacrylate monomers, radiopaque, } \\
\text { silanated fillers, initiator, stabilizers, rheological } \\
\text { additives. } \\
\text { Catalyst paste: Methacrylate monomers, radiopaque } \\
\text { alkaline fillers, initiators, stabilizers, pigments, } \\
\text { rheological additives, fluorescence dye, dual-cure } \\
\text { activator for single bond universal adhesive }\end{array}$ & $\begin{array}{l}\text { 3M ESPE, St. Paul, } \\
\text { MN, USA/3446853 }\end{array}$ \\
\hline $\begin{array}{l}\text { Bonding agent } \\
\text { Single Bond Universal } \\
\text { (Universal bonding agent) }\end{array}$ & $\begin{array}{l}\text { MDP phosphate-monomer dimethacrylate resins, } \\
\text { HEMA, vitrbond Copolymer, filler, ethanol, water, } \\
\text { initiators and silane }\end{array}$ & $\begin{array}{l}\text { 3M ESPE, St. Paul, } \\
\text { MN, USA/71009B }\end{array}$ \\
\hline
\end{tabular}

\section{Bonding procedure}

Following the pre-treatment procedures, each group was further divided into 2 subgroups $(n=5)$ according to the used luting material: subgroup (a) involves application of a self-adhesive dual-cure resin cement (G-CEM LinkAce ${ }^{\mathrm{TM}}$, GC Corp., Japan) and subgroup (b) involves application of a selfetching adhesive system (Single-bond universal, 3M ESPE, St. Paul, MN, USA) and a conventional dual-cure resin cement (RelyX ${ }^{\mathrm{TM}}$ Ultimate, 3M ESPE, St. Paul, MN, USA).

Cylinders were cut from tygon tubes (Norton Performance Plastic; Cleveland, OH, USA) with an internal diameter of $1 \mathrm{~mm}$ and a height of $2 \mathrm{~mm}$. For subgroup (a), tweezers were used to firmly hold the tubes over the specimen's surface and the self-adhesive dual cure resin cement was delivered directly from the dispensing tip into the tube till it was completely filled. The cement material was cured for $40 \mathrm{sec}$ with a light curing unit (Demetron LC, Kerr, USA) with wavelength between 350-520 $\mathrm{nm}$ and the light guide tip being held as close as possible to the opening of the tube. A radiometer (Optilux, Kerr, USA) was used to monitor the light intensity at $450 \mathrm{~mW} / \mathrm{cm}^{2}$. For subgroup (b), a universal adhesive (single-bond universal) was firstly painted on the pretreated surfaces with a microbrush then the tygon tubing was placed on the specimen surface to restrict the bonding area. After the adhesive was light cured for $20 \mathrm{sec}$, the resin cement material was injected into the tube and light cured for $40 \mathrm{sec}$. Two microcylinders were prepared on each specimen (Figure 1). The specimens were kept for one hour at room temperature, the tygon tubes were removed by carefully making two parallel cuts with number 15 scalpel blades to avoid breaking the bonded cement microcylinders. Then, the specimens were at stored $37^{\circ} \mathrm{C}$ in distilled water for $24 \mathrm{hr}$ prior to any subsequent testing. 


\subsection{Microshear bond strength $(\mu \mathrm{SBS})$ testing}

$\mu$ SBS was measured using a Universal Testing Machine (Llyod instruments Lld, fareham UK) with a load cell of $5 \mathrm{kN}$. Each acrylic block, with the embedded specimen and bonded resin cement microcylinders, was fixed to testing machine's lower fixed section. An orthodontic wire (0.014 in diameter) was used to form a loop that was positioned around and as close as possible to the base of the bonded microcylinder. The loop was adjusted so that it aligned with the loading axis of the testing machine's upper movable section (Figure 2). A shearing load with tensile mode of force was applied at a crosshead speed of $0.5 \mathrm{~mm} / \mathrm{min}$ till failure. Micro-shear bond strength was computed by dividing the maximum load before debonding (N) with the bonded area $\left(\mathrm{mm}^{2}\right)\left[\pi \mathrm{r}^{2}=3.14 *(0.5)^{2}\right.$ $=0.785 \mathrm{~mm}^{2}$ ].

The fracture patterns were evaluated and modes of failure were determined by assessing all the fractured specimens using an optical stereomicroscope (Olympus SZ61, Tokyo, Japan) at 20x magnification. The patterns of failure were categorized into; (1) Adhesive failure at the interface between the surface of the hybrid ceramic and the resin cement, (2) Block cohesive failure within the hybrid ceramic material, (3) Resin cohesive failure within the resin cement, and (4) Mixed failure (combination of the adhesive and cohesive failure modes).

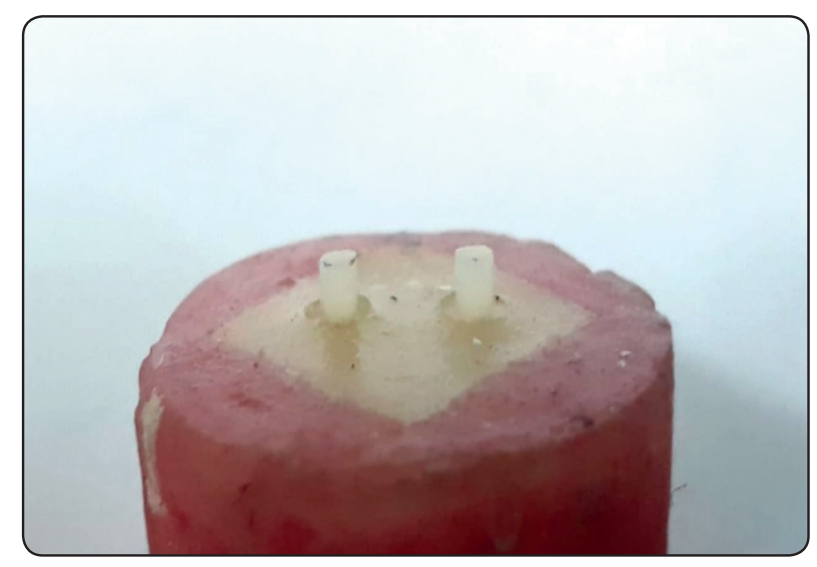

Fig. (1) Microcylinders prepared on each specimen for microshear bond strength testing.

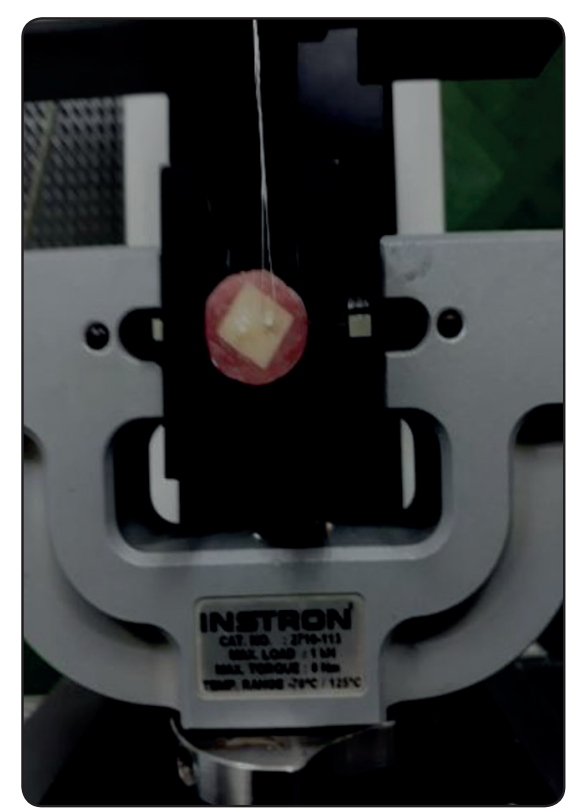

Fig. (2) Specimen mounted on Universal Testing Machine for microshear bond strength testing.

\section{Statistical analysis}

Data was first checked by the Shapiro-Wilk test for the normal distribution. Surface roughness $(\mu \mathrm{m})$ data were analyzed by one-way analysis of variance (ANOVA). $\mu \mathrm{SBS}$ (MPa) data were statistically analyzed by two-way ANOVA with the surface treatments and luting materials as the independent variables. Tukey HSD test was applied to define any significant differences among the groups. The overall $\mu$ SBS between two types of resin cements were compared by independent sample t-test. The fracture pattern was analyzed by the Chi-square $\left(\chi^{2}\right)$ test. The Statistical Package of Social Sciences (SPSS) version 21 was used at a significance level of $\alpha=0.05$.

\section{RESULTS}

\section{Surface roughness}

Means and standard deviations of surface roughness $(\mu \mathrm{m})$ for all groups are shown in Table 2 and represented graphically in Figure 3. Comparing the mean surface roughness of the tested groups showed that Group E (110 $\mu \mathrm{m}, 3.5$ bar $)$ exhibited 
the highest value $(4.41 \pm 0.45)$ compared with other surface treatment methods, while the control group showed the lowest value $(0.37 \pm 0.04)$. One-way ANOVA results of surface roughness are presented in Table 3. There was a significant difference in surface roughness among the studied groups $(\mathrm{p}<0.001)$. Tukey HSD statistical test showed a significant difference between either group $\mathrm{E}$ (110 $\mu \mathrm{m}, 3.5$ bar) or group C (50 $\mu \mathrm{m}, 3.5 \mathrm{bar})$ and other groups. However, there was no significant difference between group B $(50 \mu \mathrm{m}, 2$ bar $)$ and group D (110 $\mu \mathrm{m}, 2$ bar).

\section{SEM examination}

Figure 4 showed representative SEM micrographs of non-treated and pretreated surfaces of VE specimens. The examination displayed a difference in the surface topography of the VE specimens with the variation of parameters used

TABLE (2) Means, standard deviations and results of Tukey HSD test for surface roughness $(\mu \mathrm{m})$ of all tested groups.

\begin{tabular}{|l|l|}
\hline Groups & \multicolumn{1}{|c|}{ Mean \pm SD } \\
\hline Group A (Control) & $0.37 \pm 0.04^{\mathrm{d}}$ \\
\hline Group B $(50 \mu \mathrm{m}, 2$ bar $)$ & $2.63 \pm 0.44^{\mathrm{c}}$ \\
\hline Group C (50 $\mu \mathrm{m}, 3.5$ bar $)$ & $3.77 \pm 0.40^{\mathrm{b}}$ \\
\hline Group D $(110 \mu \mathrm{m}, 2$ bar $)$ & $3.09 \pm 0.27^{\mathrm{c}}$ \\
\hline Group E $(110 \mu \mathrm{m}, 3.5$ bar $)$ & $4.41 \pm 0.45^{\mathrm{a}}$ \\
\hline
\end{tabular}

Mean with the same superscript letter are not significantly different. during the surface treatment. As for the control group with the untreated VE hybrid ceramic surface, the recorded micrographs revealed two continuous interpenetrating networks: the ceramic network represented by the light gray areas and the polymer network represented by the dark gray areas. Several micropores were also observed on the surfaces of the specimens (Figure 4a). Regarding specimens air abraded with $\mathrm{Al}_{2} \mathrm{O}_{3}$, the images generally showed micro-sized regions of elevations and depressions with clefts and pits resulting from sandblast particles (Figures 4b-e). When $110 \mu \mathrm{m} \mathrm{Al}_{2} \mathrm{O}_{3}$ particles were used, an irregular surface with a more prominent and dispersed pattern was formed when compared to $50 \mu \mathrm{m}$ air blasting. Specimens that were 2 bar sandblasted exhibited micro-craters and pitting (Figure $4 \mathrm{~b}$ and $4 \mathrm{~d}$ ). However, larger pits and microcraters and deeper scratches were observed in specimens subjected to 3.5 bar sandblasting (Figure $4 \mathrm{c}$ and $4 \mathrm{e})$.

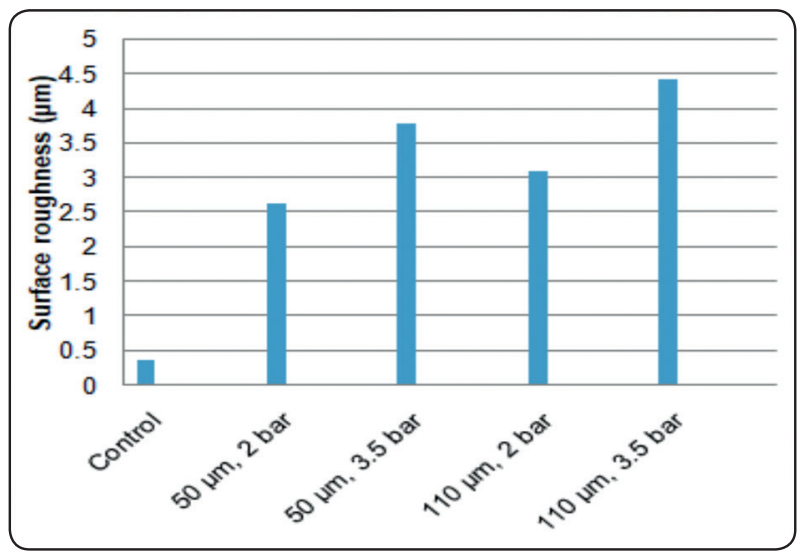

Fig. (3) Bar chart representing mean of surface roughness $(\mu \mathrm{m})$ of tested groups.

TABLE (3) One-way ANOVA results for surface roughness of different groups.

\begin{tabular}{cccccc}
\hline Source & df & Sum of Squares & Mean Square & F & P \\
\hline Between Groups & 4 & 95.088 & 23.772 & 187.891 & 0.000 \\
Within Groups & 45 & 5.693 & .127 & \\
Total & 49 & 100.782 & & \\
\hline
\end{tabular}




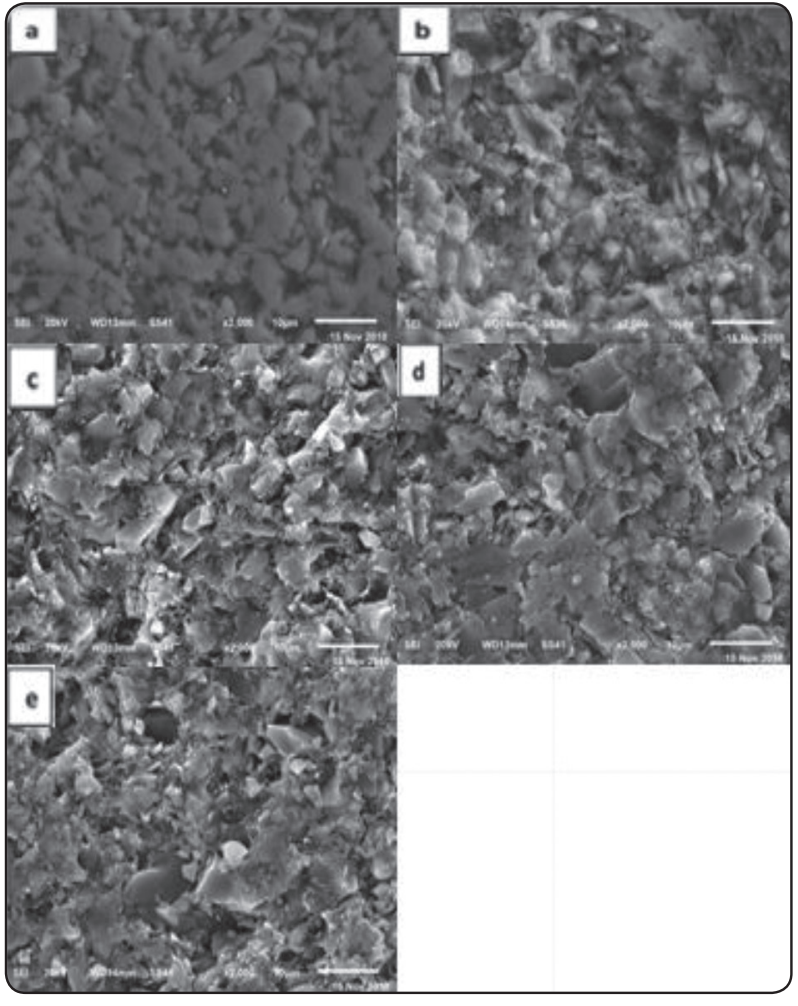

Fig. (4) SE micrographs of pretreated VE surfaces at magnification 2000x. a: Non-treated, b: $50 \mu \mathrm{m}, 2$ bar sandblasting, c: $50 \mu \mathrm{m}, 3.5$ bar sandblasting, d: $110 \mu \mathrm{m}$, 2 bar sandblasting and e: $110 \mu \mathrm{m}, 3.5$ bar sandblasting.

\section{Microshear bond strength}

Means and standard deviations of microshear bond strength (MPa) for all studied groups are shown in Table 4. A graphical presentation of these results is shown in Figure 5. Group D $(110 \mu \mathrm{m}, 2$ bar) showed the highest mean $\mu$ SBS value (RelyX Ultimate: $14.35 \pm 2.98$ and G-CEM LinkAce: $10.59 \pm 3.91$ ), while the lowest value was for control group (RelyX Ultimate: $6.11 \pm 1.59$ and G-CEM LinkAce: $4.64 \pm 1.26)$. Generally, enhancements in $\mu \mathrm{SBS}$ values (MPa) occurred in the following sequence: $110 \mu \mathrm{m}$ ( 2 bar $)>50 \mu \mathrm{m}$ ( 2 bar $)>110 \mu \mathrm{m}$ (3.5 bar) $>50 \mu \mathrm{m}$ (3.5 bar) $>$ control as shown in Table 4. Two-way ANOVA results of $\mu \mathrm{SBS}$ (MPa) are shown in Table 5. The $\mu \mathrm{SBS}$ was significantly influenced by both the type of luting material and type of treatment $(\mathrm{P}<0.05)$, whereas, there was no significant interaction between type of luting material and type of treatment $(\mathrm{P}=0.792)$. The $\mu \mathrm{SBS}$ increased at $0.2 \mathrm{MPa}$ (2 bar) abrasion pressure then decreased in the $0.35 \mathrm{MPa}$ (3.5 bar) groups, regardless the $\mathrm{Al}_{2} \mathrm{O}_{3}$ mean particle size. The $\mu$ SBS did not differ significantly between the control group and airborne abrasion groups at 0.35 $\mathrm{MPa}(\mathrm{P}>0.05)$, but was significantly higher at 0.2 $\mathrm{MPa}(\mathrm{P}<0.05)$. For the type of luting materials, RelyX Ultimate showed higher $\mu$ SBS values than G-CEM LinkAce in all studied groups. This was significant only in groups $\mathrm{B}$ and group $\mathrm{E}(\mathrm{P}<0.05)$ and non significant in other groups $(\mathrm{P}>0.05)$.

Stereomicroscopic examination at the debonding sites showed four modes of failure; adhesive failure at the bonded interface between VE blocks

TABLE (4) Means, standard deviations and results of Tukey HSD test for $\mu$ SBS (MPa) of all groups

\begin{tabular}{|c|c|c|c|c|c|}
\hline \multirow{2}{*}{ Type of luting } & \multicolumn{5}{|c|}{ Surface treatment } \\
\cline { 2 - 6 } & Control & $50 \mu \mathrm{m}, 2 \mathrm{bar}$ & $50 \mu \mathrm{m}, 3.5 \mathrm{bar}$ & $110 \mu \mathrm{m}, 2 \mathrm{bar}$ & $110 \mu \mathrm{m}, 3.5 \mathrm{bar}$ \\
\hline \multirow{2}{*}{ G-CEM LinkAce } & $4.64 \pm 1.26^{\mathrm{b}, \mathrm{A}}$ & $8.68 \pm 2.96^{\mathrm{a}, \mathrm{B}}$ & $7.49 \pm 0.83^{\mathrm{a}, \mathrm{b}, \mathrm{A}}$ & $10.59 \pm 3.91^{\mathrm{a}, \mathrm{B}}$ & $7.87 \pm 3.67^{\mathrm{a}, \mathrm{b}, \mathrm{A}}$ \\
\hline RelyX Ultimate & $6.11 \pm 1.59^{\mathrm{b}, \mathrm{A}}$ & $12.18 \pm 3.40^{\mathrm{a}, \mathrm{A}}$ & $8.64 \pm 3.68^{\mathrm{a}, \mathrm{b}, \mathrm{A}}$ & $14.35 \pm 2.98^{\mathrm{a}, \mathrm{A}}$ & $8.73 \pm 1.08^{\mathrm{a}, \mathrm{b}, \mathrm{A}}$ \\
\hline
\end{tabular}

Means with the same superscript lowercase letters (row) are not significantly different $(P>0.05)$.

Means with the different superscript uppercase letters (column) are significantly different $(P<0.05)$. 


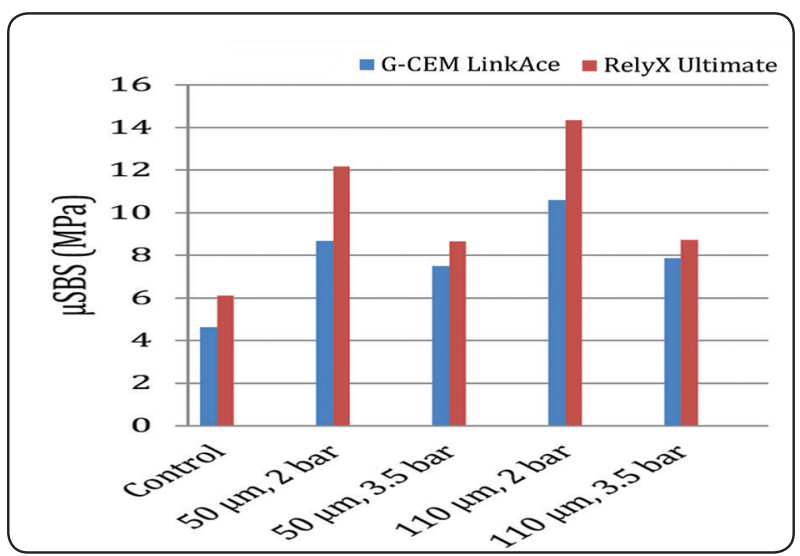

and the resin cement, cohesive failure within the block of VE hybrid ceramic, cohesive failure within the resin cement and mixed failure (mixture of cohesive and adhesive failure modes). Figure 6 shows the fracture analysis for each group. The block cohesive failure was the predominant type $(\chi 2=$ $18.57, P=.099)$ in all groups except control group which mostly showed a significant adhesive failure $(\chi 2=41.21, P<0.001)$.

Fig. (5) Bar chart representing mean of microshear bond strength $(\mathrm{MPa})$ of tested groups.

TABLE (5) Two-way ANOVA results for $\mu$ SBS (MPa) of all tested groups.

\begin{tabular}{|c|c|c|c|c|c|}
\hline Source of variation & Sum of Squares & df & Mean Square & F & P \\
\hline Luting & 40.775 & 1 & 40.775 & 5.141 & 0.032 \\
\hline Treatments & 188.119 & 4 & 47.030 & 0.421 & 0.002 \\
\hline Luting* Treatment & 13.360 & 4 & 3.340 & 7.931 & \\
\hline Errors & 206.214 & 26 & & & \\
\hline Total & 3290.202 & 36 & & \\
\hline
\end{tabular}

\section{Statistically significant difference at $P<0.05$}

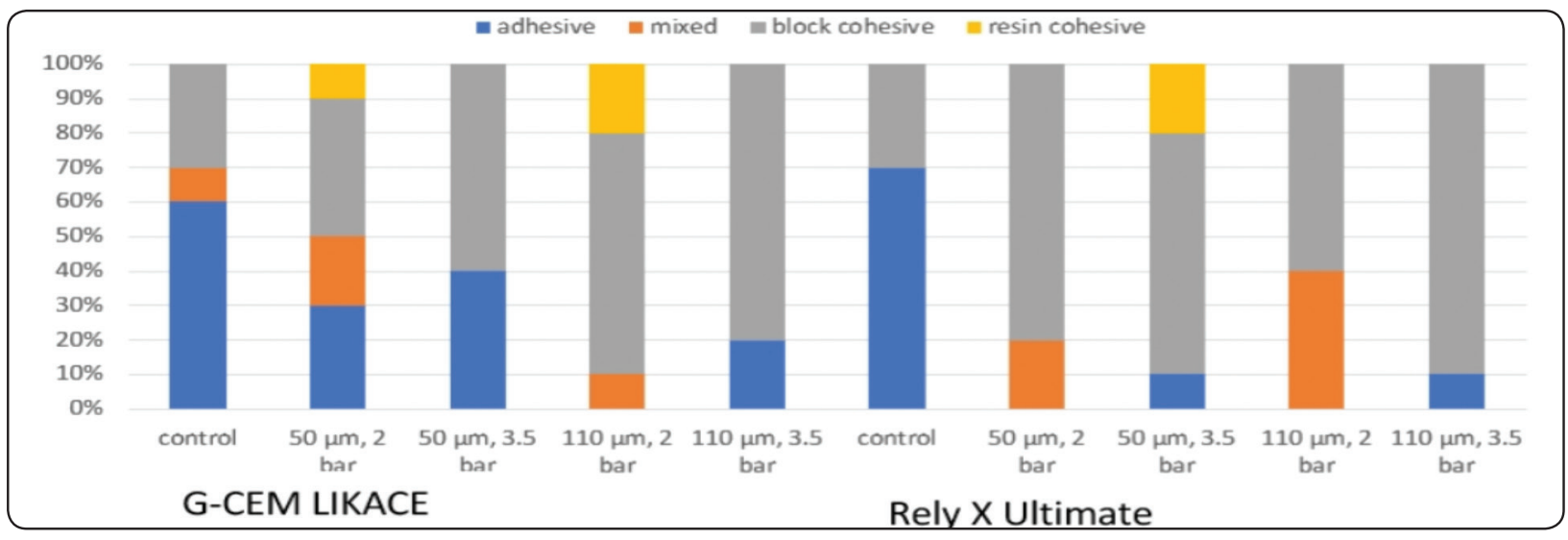

Fig (6) Distribution percentage of failure mode within different surface treatment groups 


\section{DISCUSSION}

Air abrasion has a long history of proven success in dentistry and it has been extensively used to increase the surface irregularity of a variety of substrates such as alumina ceramics, metals and acrylic materials..$^{10,17,18} \mathrm{Air}$ borne particle abrasion process has been shown effective to promote adhesion between different kinds of luting agents and a so called "hybrid CAD/CAM material" (VE). ${ }^{(13)}$ However, the impact of the different parameters of the air-abrasion process on the bonding of such materials to resin adhesives has not been reported yet. Accordingly, this study focused on the effect of varying the different parameters, including the applied pressure and abrading particle size, of the air abrasion process used in the surface pretreatment of $\mathrm{VE}$ hybrid CAD/CAM materials on the $\mu \mathrm{SBS}$ of these materials to two different kinds of resin luting agents. The results achieved in this study showed that the air-abrasion parameters affected the $\mu \mathrm{SBS}$, where the applied pressure had a significant impact on the bonding characteristics, unlike the size of the abrading particles. In addition, the resin luting materials had an impact on the bonding characteristics of VE hybrid ceramic materials. Therefore, the hypothesis of this study had to be rejected.

In this study, microshear testing was used for measurement of bond strength. This testing technique provides better control of the bonded area and eliminates the pre-stressing factors such as specimens cutting, performed in the microtensile bond strength test. ${ }^{19,20}$ The results of this study verified that specimens air abraded with $110 \mu \mathrm{m}$ alumina yielded higher $\mu \mathrm{SBS}$ values compared to that abraded with $50 \mu \mathrm{m} \mathrm{Al}_{2} \mathrm{O}_{3}$. This can be explained on the basis that air abrasion with coarser alumina particles resulted in increasing surface irregularities, which in turn increases the surface area allowed for bonding with the luting material and hence improving the micro-mechanical retention with subsequent increase in the bond strength values. ${ }^{21,22}$ This is in accordance with the results of the surface roughness testing and SEM examination which revealed that increasing the size of the particles used in air abrasion from $50 \mu \mathrm{m}$ to $110 \mu \mathrm{m}$ increased the surface roughness of the VE material. The results also showed that $\mu \mathrm{SBS}$ were higher at an abrasion pressure of $0.2 \mathrm{MPa}$ then decreased on increasing the airborne-abrasion pressure to $0.35 \mathrm{MPa}$. This may be attributed to increased surface roughness values at pressure value of $0.2 \mathrm{MPa}$ and consequently the bonding strength. Nevertheless, using excessive pressure during airborne-abrasion may introduce zones of stress concentration to the surface of the material, with the resulting formation of several sharp areas. This change in the surface topography can decrease the material's surface wettability with the formation of voids that adversely affect its bonding with the used luting agents..$^{23,24}$ Although it was demonstrated that increasing the applied abrasion pressure resulted in a significant increase in the surface roughness by both the SEM observations (Figure 4b-e) and surface-roughness analysis, the $\mu \mathrm{SBS}$ decreased and the majority of the failures that occurred were block cohesive. When the incidence of cohesive failures occurring in a bonded assembly is high, it is possible that the produced bond strength might be higher than the material's strength. Therefore, the reduction in $\mu \mathrm{SBS}$ occurring at higher level of pressure $(0.35 \mathrm{MPa})$ could be attributed to the decrease in fracture toughness and the weakening of the material caused by excessive pressure used during air-abrasion. These results are in agreement with an earlier study which investigated the impact of sandblasting pressures on the SBS of resin cement to two types of hybrid ceramics. Results revealed that the bond strength increased when the pressure was increased from 0.1 MPa to 0.2 $\mathrm{MPa}$. However, the SBS decreased when the pressure was increased to $0.3 \mathrm{MPa}$. They concluded that even when the same kind of surface pretreatment was 
applied, the bonding strength was affected by the type of material used. ${ }^{25}$

Although sandblasting is a physical/mechanical conditioning process, true chemical bond is another way of achieving and promoting adhesion between luting agents and indirect restorative materials. ${ }^{26,27}$ A critical factor in luting indirect restorations is the choice of resin cement. In the present study, two different resin cements were used; 1) a self-adhesive dual-cure resin cement and 2) a dual-cure resin cement and a self-etching adhesive system (universal adhesive system). Handling of self-adhesive resin cements is more convenient because their application does not require any pretreatment procedures, when compared to other types of luting cements. ${ }^{28}$ Additionally, when compared to autopolymerized cements, dual-curing ones were found to be more reliable and effective in bonding different indirect restorations. ${ }^{6,29}$ Universal bonding materials comprise a variety of functional constituents such as silane and 10-methacryloxydecyl dihydrogen phosphate (MDP) which helps it promote bonding in a similar manner as formerly extensively used primer. ${ }^{25}$ The results of this study showed that specimens luted with RelyX Ultimate resin cement associated with its proprietary adhesive system (Single Bond Universal) exhibited higher $\mu$ SBS values than that luted with G-CEM LinkAce resin cement in all tested groups. This may be attributed to the occurrence of chemical adhesion between specific molecules in the composition of the universal adhesive system (Single Bond Universal) like silane and the functional phosphate monomer MDP and the inorganic ceramic network on the CAD/CAM VE surface. The bifunctional silane molecules ( $\mathrm{Si}-\mathrm{O}-\mathrm{Si}$ ) (not available on the tested self-adhesive cement) are able to react with hydroxyl radical of silica present in VE inorganic structure forming networks of siloxane, and they also form a bond with metacrylate monomers present in the resin luting agent. ${ }^{30}$ Furthermore, silanes are known to increase surface wettability, improving cement penetration and de- creasing void formation. ${ }^{31}$ Additionally, MDP monomers may bond chemically to the VE surface due to a reaction between the exposed hydroxyl groups of $\mathrm{Al}_{2} \mathrm{O}_{3}$ available in the ceramic network of the material and the phosphate groups of MDP itself. ${ }^{32} \mathrm{Za}$ ghloul et al. ${ }^{33}$ reported that the application of adhesives containing silane molecules could be successfully used to produce adhesion between a composite restorative material and $\mathrm{CAD} / \mathrm{CAM}$ resin blocks for repair purposes. The results of another study that focused on the effect of sandblasting on the adhesion of hybrid ceramics and two types of cement, a selfetch dual-curing resin cement and a dual-cure resin cements, found that a high bond strength resulted (even in specimens not subjected to any surface pretreatments) when a universal bonding adhesive was applied first followed by dual-curing resin cement. ${ }^{34}$

One limitation of the present study is that only one type of hybrid ceramic block, self-adhesive resin cement and conventional resin cement were evaluated. Moreover, additional studies are necessary to investigate bond degradation under the challenging intraoral conditions.

\section{CONCLUSION}

Within the limitations of this study and based on the results, the following conclusions can be made.

1. Increasing the airborne-abrasion pressure considerably increased the surface roughness of the tested groups $(\mathrm{p}<0.001)$.

2. Higher $\mu \mathrm{SBS}$ could be achieved through moderate degree of roughness rather than smooth or exaggerated rough surfaces.

3. RelyX Ultimate luting agent in association with its universal adhesive system exhibited higher $\mu \mathrm{SBS}$ values compared to G-CEM LinkAce.

\section{Conflict of interest}

The authors declared no potential conflicts of interest. 


\section{REFERENCES}

1. Lauvahutanon S, Takahashi H, Shiozawa M, et al. Mechanical properties of composite resin blocks for CAD/ CAM. Dent Mater J 2014;33:705-710.

2. Conrad HJ, Seong WJ, Pesun IJ. Current ceramic materials and systems with clinical recommendations: a systematic review. J Prosthet Dent 2007;98:389-404.

3. Lim HN, Yu B, Lee YK. Spectroradiometric and spectrophotometric translucency of ceramic materials. J Prosthet Dent 2010;104:239-246.

4. Coldea A, Swain MV, Thiel N. Mechanical properties of polymer-infiltrated-ceramic-network materials. Dent Mater 2013;29:419-426.

5. Ozarslan MM, Buyukkaplan US, Barutcigil C, et al. Effects of different surface finishing procedures on the change in surface roughness and color of a polymer infiltrated ceramic network material. J Adv Prosthodont 2016;8:16-20.

6. Elsaka SE. Bond strength of novel CAD/CAM restorative materials to self-adhesive resin cement: the effect of surface treatments. J Adhes Dent 2014;16:531-540.

7. Bojemüller E, Coldea A. VITA ENAMIC TechnicalScientific Documentation. Bad S“ackingen, Germany, VITA Zahnfabrik, 2012.

8. Behr M, Rosentritt M, Regnet T, Lang R, Handel G. Marginal adaptation in dentin of a self-adhesive universal resin cement compared with well-tried systems. Dent Mater 2004;20:191-197.

9. Blatz MB, Sadan A, Kern M. Resin-ceramic bonding: a review of the literature. J Prosthet Dent 2003;89:268-274.

10. Soares CJ, Soares PV, Pereira JC, et al. Surface treatment protocols in the cementation process of ceramic and laboratory-processed composite restorations: a literature review. J Esthet Restor Dent 2005;17:224-235.

11. Elsaka SE. Repair bond strength of resin composite to a novel CAD/CAM hybrid ceramic using different repair systems. Dent Mater J 2015;34:161-167.

12. Secilmis A, Ustun O, Buyukhatipoglu IK. Evaluation of the shear bond strength of two resin cements on different CAD/CAM materials. J Adhes Sci Tech 2016;30:983-993.

13. Güngör MB, Nemli SK, Bal BT, Ünver S, Doğan A. Effect of surface treatments on shear bond strength of resin composite bonded to $\mathrm{CAD} / \mathrm{CAM}$ resin-ceramic hybrid materials. J Adv Prosthodont 2016;8:259-266.
14. Elsaka SE. Influence of surface treatments on bond strength of metal and ceramic brackets to a novel CAD/CAM hybrid ceramic material. Odontology 2016;104:68-76.

15. Barutcigil K, Barutcigil C, Kul E, O”zarslan MM, Buyukkaplan US. Effect of different surface treatments on bond strength of resin cement to a CAD/CAM restorative material. J Prosthodont 2019;28:71-8.

16. Stawarczyk B, Taufall S, Roos M, Schmidlin PR, Lümkemann N. Bonding of composite resins to PEEK: the influence of adhesive systems and air-abrasion parameters. Clin Oral Invest 2018;22:763-71

17. Friederich R, Kern M. Resin bond strength to densely sintered alumina ceramic. Int J Prosthodont 2002;15:3338 .

18. Ozcan M, Valandro LF. Bond strength of two resin cements to titanium after different surface conditioning methods. Gen Dent 2012;60:e6-e12.

19. Armstrong S, Geraldeli S, Maia R, Raposo LH, Soares CI, Yamagawa J. Adhesion to tooth structure: a critical review of "micro" bond strength test methods. Dent Mater 2010;26:50-62.

20. Scherrer SS, Cesar PF, Swain MV. Direct comparison of the bond strength results of the different test methods: a critical literature review. Dent Mater 2010;26:78-93.

21. Benetti PA, Della Bona A, Kelly JR. Evaluation of thermal compatibility between core and veneer dental ceramics using shear bond strength test and contact angle measurement. Dent Mater 2010;26:743-750.

22. Hallmann L, Mehl A, Sereno N, H€ammerle CH. The improvement of adhesive properties of PEEK through pretreatments. Appl Surf Sci 2012;258:7213-7218.

23. Amaral R, Ozcan M, Bottino MA, Valandro LF. Microtensile bond strength of a resin cement to glass infiltrated zirconia reinforced ceramic: the effect of surface conditioning. Dent Mater 2006;22:283-90.

24. Pollington S, Fabianelli A, van Noort R. Microtensile bond strength of a resin cement to a novel fluorcanasite glass ceramic following different surface treatments. Dent Mater 2010;26:864-72.

25. Kim JE, Kim JH, Shim JS, Roh BD, Shin Y. Effect of air-particle pressures on the surface topography and bond strengths of resin cement to the hybrid ceramics. Dent Mater J 2017;36:454-60. 
26. Lehmann F, Kern M. Durability of resin bonding to zirconia ceramic using different primers. J Adhes Dent 2009; $11: 479-83$.

27. Stefani A, Brito RB, Kina S, Andrade OS,Ambrosano GM, Carvalho AA, et al. Bond Strength of Resin Cements to Zirconia Ceramic Using Adhesive Primers. J Prosthodont 2016;25:380-5.

28. Ferracane JL, Stansbury JW, Burke FJT. Self-adhesive resin cements-chemistry, properties and clinical considerations. J Oral Rehabil 2011;38:295-314.

29. Elsaka SE. Effect of surface treatments on the bonding strength of self-adhesive resin cements to zirconia ceramics. Quintessence Int 2013; 44: 407.

30. Matinlinna JP, Vallittu PK. Silane based concepts on bonding resin composite to metals. J Contemp Dent Pract 2007;8:1-8.

31. Re D, Augusti D, Sailer I, Spreafico D, Cerutti A. The effect of surface treatment on the adhesion of resin cements to Y-TZP. Eur J Esthet Dent 2008;3:186-96.

32. Ozcan M, Bernasconi M. Adhesion to zirconia used for dental restorations: a systematic review and meta-analysis. J Adhes Dent 2015;17:7-26.

33. Zaghloul H, Elkassas DW, Haridy MF. Effect of incorporation of silane in the bonding agent on the repair potential of machinable esthetic blocks. Eur J Dent 2014;8:44-52.

34. Augusti D, Gabriele A, Francesca C, Dino R. Does sandblasting improve bond strength between nano-ceramic resin and two different luting composites. Bioceram Dev Appl 2015;5:1-5. 